\title{
RADIOIODINE THERAPY IN GRAVES' DISEASE
}

\author{
A REVIEW
}

\author{
By MAYO H. SOLEY ${ }^{1}$ AND NADINE FOREMAN 2
}

(From the Department of Medicine, State University of Iowa, College of Medicine, Iowa City)

HISTORICAL

The discovery of radioactive isotopes of iodine by Fermi (1) in 1934 was followed in 1938 by the use of these tagged atoms in studies of the physiology of the thyroid in human and other animals $(2,3)$. The selective deposition of radioiodine in the thyroid and the known effectiveness of radiation therapy in selected patients with Graves' disease soon led to the use of two radioactive isotopes of iodine in the treatment of thyrotoxicosis: $\mathrm{I}^{130}$ with a half-life of 12.6 hours and $\mathrm{I}^{131}$ with a halflife of eight days. Hertz and Roberts (4) first used this method of therapy in the spring of 1941. Hamilton and Lawrence (5) treated their first patients in the fall of 1941 and Chapman and Evans. (6) took over the work of Hertz and Roberts (7) in 1943. The earliest reports to allow an even tentative appraisal of radioiodine therapy were published by the latter groups of authors in 1946 (6, $7)$. In 1948, Soley and Miller $(8,9)$, published their experiences and later in the same year two other groups recorded their results (Haines, Keating, Power, Williams and Kelsey [10]; Werner, Quimby and Schmidt [11, 12, 13]). Prinzmetal and his coworkers $(14,15)$ and Crile (16) contributed their material in 1949.

\section{PERSON NEL}

Radioiodine as a therapeutic agent in Graves' disease is still in the experimental stage and much remains to be learned about its clinical use, its immediate biological effects, and its long-time effects, both upon the thyroid and upon the patient as a whole. Certain skilled personnel are essential to any program dealing with radioiodine since it is a form of radiation therapy. Such a program may be divided into three general phases : radiological, physical and clinical. There can be no doubt but that the very important problems of radiation

1 Deceased; formerly Research Professor of Medicine and Dean, State University of Iowa, College of Medicine.

2 Research Assistant in Medicine, State University of Iowa, College of Medicine. dosimetry and biological effects of ionizing radiations should be handled by a radiologist. The technical problems relating to the physical measurements of radiation, to the maintenance and operation of electronic equipment, and monitoring of the laboratory areas are most capably handled by a physicist. As is always true in medicine, it is important to render care to the patient as a whole. In prescribing a relatively new and powerful remedy, the clinician must make frequent and careful appraisals during the course of treatment and in the long term follow-up of treated patients.

\section{RADIATION EFFECTS OF $I^{131}$}

Although no serious toxic effects have been observed as yet in patients receiving $\mathrm{I}^{\mathbf{1 3 1}}$ therapeutically, thyroidal and extrathyroidal changes have been found in experimental animals.

Gorbman (17) gave young mice $3-55 \mathrm{mc}$. per $\mathrm{kg}$. of $\mathrm{I}^{131}$ to study the effects on the thyroid and adjacent tissue. Within the first day the striking effect was periglandular edema with infiltration by lymphocytes, polymorphonuclear and mast cells. Changes in cells of tracheal epithelium were common. At the end of two days with large doses (53 mc. per kg.) the thyroid was an eosinophilic mass with recognizable follicles only in the peripheral parts of the gland. After three days destruction of the thyroid was complete when $50 \mathrm{mc}$. per $\mathrm{kg}$. were administered and minimal with the lowest dosage. Comparable changes were noted in parathyroids. Over $20 \mathrm{mc}$. per $\mathrm{kg}$. caused histologic damage to the recurrent laryngeal nerves. At the end of 24 days as little as $3-5 \mathrm{mc}$. per $\mathrm{kg}$. caused extensive destruction of the thyroid; 18 22 mc. produced complete thyroid destruction. After an interval of 120 days, the thyroid was only a shrunken fibrous band, except in those animals who had received the smallest amounts of $\mathrm{I}^{131}$.

The University of California investigators (8, 9) found extensive but not complete thyroid destruction by the 30th to 40th days in rabbits from the effects of $300 \mu \mathrm{c}$. per $\mathrm{kg}$. with approxi- 
mately a $50 \%$ decrease in size of the thyroid glands. The thyroid of one dog sacrificed one hundred days after a similar dose showed fibrosis of vessels as well as the glandular tissue. No other tissues of any of these animals showed changes except the renal tubules of one of the rabbits.

Findlay and LeBlond (18) gave 60-80 $\mu \mathrm{c}$. of $\mathrm{I}^{\mathbf{1 3 1}}$ to rats previously fed low iodine diets and found less marked histologic changes than those reported by Gorbman in his mice treated with 3 mc. per $\mathrm{kg}$. These findings are consistent with the low dosage used.

If a direct comparison could be made between results in animals and in man, from 210 to 3,500 mc. would be required to produce total thyroid and parathyroid destruction in an average adult of $70 \mathrm{~kg}$., or from ten to 175 times the usual maximum dose used in the treatment of Graves' disease. This safety factor is far greater than is usual with most therapeutic agents.

\section{CALCULATION OF I ${ }^{131}$ DOSAGE}

The subject of isotope dosimetry has been well covered by Marinelli (19), Quimby (20), and Marinelli, Quimby and Hine (21), the details of which are beyond the scope of this paper. It is of importance, however, to have some concept of the amount of radiation administered during the course of $I^{181}$ therapy. Only then can conclusions be drawn as to the effectiveness of the method and comparisons between groups of patients be made.

$\mathrm{I}^{131}$ gives off two kinds of radiation, beta particles with maximum energy of $0.6 \mathrm{MEV}$ (million electron volts) and gamma rays with energies of 0.37 and $0.08 \mathrm{MEV}$. Beta particles have a maximum range of approximately $2.5 \mathrm{~mm}$. in tissue and most of their energy is thus expended within the thyroid. Gamma rays are more penetrating and produce but little radiation effect within the thyroid gland.

It is both simple and convenient to accept the following formula for the calculation of equivalent roentgens delivered to the thyroid by $\mathrm{I}^{181}$ (beta and gamma).

$$
\begin{aligned}
\text { Dose e. } r=\frac{\mu \mathrm{c} . \text { administered }}{} \times \text { uptake } \% & \\
\text { grams of thyroid } & \times \frac{\text { Biol. H.L. }}{8} \times 160
\end{aligned}
$$

The dosage depends, then, upon the concentration of radioiodine within the thyroid, upon the half-life of the isotope, and upon the rate at which the radioiodine leaves the thyroid (the biological half-life). The figure " 160 " represents the approximate no. of equivalent roentgens produced when $1 \mu \mathrm{c}$. of $\mathrm{I}^{131}$ undergoes total decay. The calculation of tissue dosage assumes that the distribution of the isotope within the thyroid is uniform (even though this is not always the case) and that each retained iodine atom decays completely. The calculation of radiation dosage in this relatively easy way is of practical value even though it may lack absolute precision.

\section{TECHNIQUE OF TREATMENT}

$I^{131}$ is administered orally. Single doses have ranged from 1.0 to $20.0 \mathrm{mc}$. with good therapeutic results with 2.0 to $12.0 \mathrm{mc}$. It is obvious that the amount of radioiodine taken up by the thyroid rather than the size of the oral dose is the important factor in determining the amount of radiation to the thyroid. Therefore, most workers have attempted to estimate the weight of the goiter, have measured the uptake of radioiodine by the thyroid gland and then have analyzed the therapeutic results in terms of the number of microcuries of radioactive iodine per gram of thyroid tissue. Haines and his coworkers (10) have devised a simple formula for the calculation of a desired dose:

Microcuries desired per gram of tissue $\times$ Estimated weight of thyroid in grams $\times 100$ per cent of $I^{131}$ tracer collected by thyroid

This gives the total desired dose in microcuries.

The dose per gram of thyroid in the $83 \%$ of patients who have had good therapeutic results has been from 23.0 to $574.0 \mu \mathrm{c}$. Werner, Quimby and Schmidt (11) state that doses of $100 \mu \mathrm{c}$. per gram or more are generally adequate, since 24 of 27 patients returned to normal with a single dose of this size. However, no absolute rules can be made and the problem of dosage must ultimately fall upon sound clinical judgment rather than upon simplified formulations.

\section{SELECTION OF PATIENTS}

Probably because of the relatively short period of experience with radioiodine for therapeutic use the common denominator in the selection of patients seems to be the unquestioned diagnosis of toxic goiter. The Massachusetts General Hospital group prefer to limit their patients to those over 45 years of age since the possibility of late neoplastic change becomes more important in young patients.

Haines, Keating and coworkers (10) decided "to give therapeutic doses of radioiodine only to those persons for whom the risk and difficulties of other methods of treatment appeared to us (them) to be excessive" and included in their series patients with serious heart disease or other complications which added considerably to the surgical risk, and patients who had recurrent exophthalmic goiter, especially if the latter had had multiple resections of the thyroid and unilateral paralysis of a vocal cord or if extremely small amounts of thyroid gland remained. Their pa- 
tients represent therefore ones whose disease had proved resistant to other forms of therapy.

Werner, Quimby and Schmidt (13) have selected patients as young as 18 years of age and have included in somewhat less than half of their series patients with hyperthyroidism, recurrent post-operatively, who had been treated with antithyroid drugs for some time without satisfactory relief. All but one of their patients had toxic diffuse goiter and none had true hyperophthalmic goiter.

Crile (16) has followed 22 of his 50 patients long enough to report results of radioiodine therapy. Of these 22 , ten had toxic nodular and 12 toxic diffuse goiter. His patients with nodular goiter required larger doses and were more difficult to control than his other group. In addition, the nodular goiters did not decrease as readily in size.

The University of California group have used the following criteria in selecting patients for radioiodine therapy: (1) Definite primary hyperthyroidism up to moderately severe degree; (2) thyroid enlargement not much greater than 80 grams; (3) recurrent hyperthyroidism in patients who have had one or more thyroidectomies with or without parathyroid deficiency or recurrent laryngeal palsies and (4) severe exophthalmos when roentgen therapy seems inadvisable because of the large amount of thyroid tissue present. This group has considered certain factors contraindications to radioiodine therapy: $(a)$ the presence of a nodular goiter; $(b)$ extremely large thyroids with or without pressure symptoms; $(c)$ severe thyrotoxicosis with complications since antithyroid drugs and other measures in conjunction with radioiodine probably provide a safer approach than radioiodine alone; $(d)$ pregnancy ; and (e) previous treatment with ordinary iodine unless there is adequate uptake of radioiodine by the thyroid. Prinzmetal, Agress, Bergman and Simkin $(14,15)$ also feel that patients with toxic nodular goiter should not be treated with radioiodine.

In summary, there are no hard and fast rules concerning selection of patients and many of the differences noted by groups of investigators are more apparent than real. Even after prolonged and extensive experience with any therapy in any disease, there will be legitimate differences of opinion as to the best of several effective methods.

\section{RESULTS OF TREATMENT OF GRAVES' DISEASE WITH RADIOIODINE $I^{131}$}

The earliest published series of cases is that of Hertz and Roberts (7) who used $\mathrm{I}^{130}$, with a halflife of 12.6 hours (see Table I). Chapman, Skanse and Evans (22) have also reported on the treatment of 65 cases of hyperthyroidism with $I^{130}$ and their results are also included in Table I. In their group of 20 cases, Hertz and Roberts (7) followed radioiodine with a course of treatment with ordinary iodine $\left(\mathrm{I}^{127}\right)$. This was done so that no harm would result to the patient from prolonged thyrotoxicosis should the radioiodine prove ineffective in controlling the disease. It was thought also that the $\mathrm{I}^{127}$ might delay the release of radioiodine from the thyroid during treatment. In this respect, their series is not strictly comparable to that of Chapman, Skanse and Evans (22) who used $I^{130}$ only but it appears likely from the published results that the major effects produced in those 20 cases were due to the radioactive

TABLE I

Treatment of Graves' disease with $\Gamma^{130}$

\begin{tabular}{|c|c|c|c|}
\hline & I & II & III \\
\hline & $\begin{array}{c}\text { Hertz and } \\
\text { Roberts } \\
(7)\end{array}$ & $\begin{array}{c}\text { Chapman } \\
\text { and Evans } \\
\text { (6) }\end{array}$ & $\begin{array}{c}\text { Chapman, } \\
\text { Skanse } \\
\text { and Evans } \\
\text { (22) }\end{array}$ \\
\hline Number of patients & 20 & 22 & $65^{*}$ \\
\hline $\begin{array}{l}\text { Mean values } \\
\text { Estimated wt. of thyroid } \\
\text { before treatment }\end{array}$ & $51.3 \mathrm{gm}$. & $53.4 \mathrm{gm}$. & $45 \mathrm{gm}$. \\
\hline BMR before treatment & $41.5 \%+$ & $39 \%+$ & - \\
\hline BMR after treatment & $6.25 \%+t$ & $1.4 \%+$ & - \\
\hline Total dose I 180 & $10.8 \mathrm{mc}$. & - & $32 \mathrm{mc}$. \\
\hline $\begin{array}{l}\text { Estimated dose in } \mu \mathrm{c} . / \mathrm{gm} \text {. } \\
\text { of thyroid }\end{array}$ & - & 860 & 450 \\
\hline $\begin{array}{l}\text { Time to return to normal } \\
(\mathrm{mo.})\end{array}$ & 一 & $2 \frac{1}{3}$ & 2 \\
\hline $\begin{array}{l}\text { Myxedema or hypo- } \\
\text { thyroidism }\end{array}$ & - & 2 & 11 \\
\hline Radiation sickness & - & 3 & 6 \\
\hline
\end{tabular}

* This group of 65 includes the 22 cases listed in column II.

† Done from 3 mo. to $4 \frac{1}{2}$ yrs. after treatment. 
rather than to the inert iodine. Hertz and Roberts (7) reported on an additional nine cases in which $\mathrm{I}^{180}$ was not given with therapeutic intent and they, therefore, have been omitted from this series. The disadvantages in the use of $\mathrm{I}^{130}$ are the necessity for being near to its place of production (due to short half-life) and the more frequent production of radiation sickness because of rapid delivery of radiation and rapid destruction of thyroid tissue. It should be noted here that radioiodine which is produced by the cyclotron contains a mixture of isotopes, approximately $90 \%$ of which is $\mathrm{I}^{130}$ and $10 \% \mathrm{I}^{181}$; thus much of the radiation effect could have been from the $\mathrm{I}^{131}$.

When the longer-lived isotopes $\mathrm{I}^{131}$ (half-life, eight days) became more generally available, several groups began treating thyrotoxic patients in various parts of the country $(8-11,13-16,22)$. A discussion of the use of this isotope is the primary aim of this paper. The results of therapy with $\mathrm{I}^{131}$ in some 288 cases are presented in summary form in Table II. It becomes apparent that considerable variation in methods and in results of treatment among the several groups occurs and this fact is worthy of some comment.

Haines, Keating et al. (10) at the Mayo Clinic in their treatment of more severe and complicated cases, used relatively large, single doses of $\mathrm{I}^{131}$.
"A result was considered good if the basal metabolic rate was lowered to plus $15 \%$ or further and if the clinical evidences indicated that the patient was in a euthyroid state. Results were classified as fair when the severity of hyperthyroidism was markedly reduced by treatment." Twenty-seven of 40 patients had good results according to their criteria, eight were classified as fair results, and five were failures. Seven of 40 cases (17.5\%) developed myxedema following treatment. In view of the nature of the patients treated it obviously was better to overshoot than to undershoot the mark in therapy.

Werner, Quimby and Schmidt (13) at Columbia University reported upon the results of treatment of 58 patients with $\mathrm{I}^{131}$ with follow-up studies of from four months to over one year (not included in Table II because of incomplete published data). The average total dosage used was from 3 to 4 mc. with 22 of the 58 patients requiring more than a single therapeutic dose. Forty-eight of 56 patients are now in remission, a case success rate of $86 \%$. Two patients have not been followed sufficiently since the last treatment to permit evaluation. Four cases became hypothyroid for a short period of time but recovered. The average time required to reach normal metabolic levels following treatment was three months. Nearly $50 \%$ of

TABLE II

Treatment of Graves' disease with radioiodine (Is1)

\begin{tabular}{|c|c|c|c|c|c|c|c|c|}
\hline \multirow[b]{2}{*}{$\begin{array}{l}\text { Number of patients } \\
\text { Mean values } \\
\text { Est. wt. of thyroid before treatment } \\
\text { (gm.) } \\
\text { Est. wt. of thyroid after treatment } \\
\text { BMR before treatment } \\
\text { BMR after treatment } \\
\text { Prot-bound iodine before treatment } \\
\text { ( } \mu \text { c. \%) } \\
\text { Prot-bound iodine after treatment } \\
\text { Total dose Iim }(\mu \mathrm{c} .) \\
\text { Estimated } \mu \mathrm{c} . / \mathrm{gm} \text {. of thyroid for total } \\
\text { dose }\end{array}$} & $\begin{array}{c}\text { I } \\
\begin{array}{c}\text { Chapman, } \\
\text { Evans and } \\
\text { Skanse }\end{array} \\
\\
65\end{array}$ & \multicolumn{2}{|c|}{ Soley and Miller } & $\begin{array}{c}\begin{array}{c}\text { III } \\
\text { Haines, } \\
\text { Keating } \\
\text { et al. }\end{array} \\
\\
40\end{array}$ & \multicolumn{2}{|c|}{ Crile } & \multicolumn{2}{|c|}{$\underset{\text { Prinzmetal et al. }}{\mathrm{V}}$} \\
\hline & $\begin{array}{c}50 \mathrm{gm} . \\
= \\
\bar{Z} \\
10,000 * \\
140 \\
2 \\
4 \\
0 \\
0 \\
56 / 65-86 \% \\
8 / 65-12.3 \%\end{array}$ & $\begin{array}{c}31.4 \\
13.1 \\
28.3+ \\
1- \\
10.7 \\
5.8 \\
3,067 \\
67 \\
67 \\
\text { (42 cases) } \\
3.4\end{array}$ & $\begin{array}{c}49.1 \\
19.0 \\
39+ \\
6.8+ \\
13.7 \\
7.7 \\
7,556 \\
162 \\
\text { (4 cases) } \\
14.6\end{array}$ & $\begin{array}{c}27.6 \\
\text { smaller } \\
35+ \\
5.7+ \\
= \\
= \\
230.65^{*} \\
2.67 \\
7 \\
1 ? \\
3 \\
27 / 40-67.5 \% \\
8 / 40-20 \% \\
5 / 40-12.5 \%\end{array}$ & $\begin{array}{c}61 \\
28 \\
47+ \\
2+ \\
= \\
7,200 \\
- \\
4 \\
1 \\
0 \\
0 \\
11 / 12-91.5 \% \\
1 / 12-8.5 \%\end{array}$ & $\begin{array}{c}115 \\
80 \\
48+ \\
24+ \\
- \\
10,900 \\
- \\
0 \\
0 \\
0 \\
0 \\
4 / 10-40 \% \\
6 / 10-60 \%\end{array}$ & $\begin{array}{c}\text { uncomplic. } \\
26 \\
38.7 \\
20 \\
- \\
11.3 \\
6.3 \\
4.400 \\
- \\
3-4 \\
4 \\
0 \\
1 \\
25 / 26-96 \% \\
1 / 26-4 \%\end{array}$ & $\begin{array}{c}\text { complic. } \\
18 \\
\\
42.3 \\
20(?) \\
37.5+ \\
0 \\
11.5 \\
6.3 \\
5,320 \\
- \\
4.1 \\
(17 \text { cases }) \\
0 \\
0 \\
0 \\
16 / 18-89 \% \\
2 / 18-11 \%\end{array}$ \\
\hline
\end{tabular}

* Single dose. 
their patients represented recurrent hyperthyroidism after operation; they were not considered to be good surgical risks, and, for the most part, had not come into remission with antithyroid drugs or with X-ray therapy.

Sixty-one patients have been treated at the University of California Hospital $(8,9)$. Each of the patients treated had either primary or recurrent Graves' disease of mild to moderately severe degree. When the percentage uptake of iodine by the thyroid had been determined, it was possible to make an estimate of the probable optimal dosage of iodine needed, since it could be shown that, over a short period of time, the uptake of a large (therapeutic) dose as a rule would be the same as that of a small (tracer) dose. Following treatment, patients were re-evaluated at two to four week intervals and second, third, or fourth treatments were given as necessary. The usual interval between treatments was from four to six weeks. A good result was one in which complete remission of the signs and symptoms of Graves' disease occurred with return of the thyroid to normal size within a reasonable length of time, irrespective of the number of doses required. Of the 61 cases which now have been reported, 51 , or $84 \%$, were considered to be good results. The remaining ten patients $(16 \%)$ were reported as fair results due to the fact that they were under treatment for a long period of time before reaching the euthyroid state. It is apparent that these ten patients represent, on the average, a more severe degree of hyperthyroidism and that larger doses of radioiodine were necessary for the control of their disease. At least a part of the difficulty lay in the fact that $\% / 10$ of these patients were treated rather early in the course of this study when only limited amounts of iodine were available and when low dosage schedules were being used. Three patients could not be followed or evaluated properly and represent therapeutic failures. The first was a 35 year old woman with severe Graves' disease. She received a total of $4 \mathrm{mc}$. of $\mathrm{I}^{131}$ in two doses, with return to normal thyroid status within two months of the beginning of therapy. Two months later she developed an acute rheumatic pancarditis and it became impossible to appraise her thyroid status accurately. The second case was a 53 year old woman with symptoms and signs of hyperthyroidism, with goiter, elevated BMR and high protein-bound iodine. She was given a total of $6 \mathrm{mc}$. of $\mathrm{I}^{181}$ without improvement in her clinical condition. She later underwent a subtotal thyroidectomy at another hospital and the thyroid was found to be nodular and fibrotic. The third failure was a woman whose treatment for Graves' disease with radioiodine was interrupted by the development of a major psychotic episode. The latter two patients were not included in the tabulated results.

The 65 cases reported by Chapman, Skanse, and Evans (22) of the Massachusetts General Hospital are quite comparable with those from the University of California. Although the average total dose of radioiodine (in millicuries) exceeds that given the University of California group and was administered as a single dose, the estimated number of microcuries per gram of thyroid is quite similar, as are the results of treatment. ${ }^{8}$ Fiftysix of the 65 patients experienced good results following $\mathrm{I}^{181}$ therapy whereas eight of 65 were improved but not clinically well six months after treatment. Four of their cases developed hypothyroidism but there were no other complications. One of the 65 died of myocardial infarction shortly after treatment and therefore is omitted from the tabulated results.

Crile (16), at the Cleveland Clinic, has treated 50 patients with radioiodine and has reported upon the results in 22 cases who have been followed for from three to ten months. Twelve patients had diffuse toxic goiter and the remaining ten toxic nodular goiter. Eleven of the 12 patients in the first group responded well to treatment, with relief of symptoms of hyperthyroidism and a significant decrease in thyroid size. Only one patient in this group was not classified as a good result even though much improved. Because of the relatively short period of follow-up, it is perhaps not justifiable to class this as a poor result. The patients with toxic nodular goiter have proven considerably more difficult to control by this method of therapy; they require larger doses of radioiodine to produce a remission in their disease, the length of time required to bring about improvement is longer,

8 At the time that these studies were carried out, the millicurie as measured at the University of California apparently was about $2 \frac{11}{2}$ times that of the Massachusetts General Hospital; consequently the average total dosage is more nearly the same than would appear from the data. 
and the nodular thyroid does not decrease as readily in size. Of ten such cases, only four (40\%) have made a clinical recovery while the remaining six are still under treatment. (Results tabulated in Table II.)

Prinzmetal and co-workers $(14,15)$ have compiled complete data on 44 patients, all of which have been followed for more than one year. Twenty-six were uncomplicated cases of Graves' disease, comparable with those of the University of California group. Using a schedule of multiple, relatively conservative doses, Prinzmetal succeeded in producing satisfactory remissions in 25 of 26 patients within three to four months. The last patient of the group is reported to be improved, but not completely well after one year of study. "Three patients developed hypometabolism and one patient developed signs and symptoms of myxedema. One patient who apparently relapsed had complete return to normal after further iodine administration." The remaining 18 cases presented one or more rather serious complications in addition to their hyperthyroidism. Of the group, 16 (89\%) became relieved of their thyrotoxicosis within four months, on the average. One patient did not respond at all and another was improved only moderately.

The overall incidence of clinically good results in the 288 hyperthyroid patients summarized is $83 \% ; 9.7 \%$ can be classed as fair results; $5.5 \%$ as failures. Results of treatment of toxic nodular goiter with radioiodine have been relatively disappointing since only four out of ten did well.

Some attempt should be made to explain the differences in results obtained in patients when equal quantities of radioiodine are given, and in various series of patients who presumably are handled in the same way. Probably not a great source of discrepancy is the variability of standardization of the iodine at different institutions throughout the country. The major difficulty lies in the calculation of radiation dosage for any given patient. Apart from the factors of physical characteristics of the administered radiation, dosage is dependent upon (1) the percentage which is taken up and held by the thyroid, (2) the size of the gland in which the iodine is distributed, and (3) the rate at which the iodine leaves the thyroid. The greatest source of error is, of course, in the estimation of thyroid size, a subjective error which cannot readily be measured. Even if it were possible to guess accurately the weight of the thyroid, certain differences in therapeutic results would be observed due to variations in response to a given amount of radiation in individual patients. Hence, as has been reported by several groups (8-13), myxedema may follow relatively small doses of radioiodine (in $\mu$ c. per gram) while patients receiving much greater amounts do not go below normal metabolic levels.

\section{COMPLICATIONS}

Certain phenomena seen within the immediate post-therapy period are worthy of comment but do not constitute true complications. Within the first two to three days, spontaneous tenderness in the thyroid or tenderness on palpation may be noted and this coincides with an increase in the sedimentation rate. This is seen mainly after single doses of two or more millicuries of $\mathrm{I}^{\mathbf{1 3 1}}$.

Within the first one or two weeks after $\mathrm{I}^{181}$ has been administered, some increase in the severity of thyrotoxic symptoms may occur and is associated with a rise in the protein-bound iodine in the blood. Werner, Quimby and Schmidt (11) state that the average increase in the basal metabolic rate in three patients was $15 \%$. The mechanism of the exacerbation probably is rapid radiation destruction of the thyroid and release of stored hormone.

Patients and examiners alike are apt to find that the thyroid becomes firm and even hard within a few days after therapy. This may be associated with a sore throat and cough, the latter persisting for several weeks.

In only one instance has radiation sickness been noted (10), and this was questionable. This is in distinct contrast with the findings of Chapman and Evans (6) who observed radiation sickness in six of 65 patients treated with $\mathrm{I}^{130}$.

Transient hypothyroidism has been seen in four of 58 patients (13), actual hypothyroidism in three of 26 patients $(14,15)$ and myxedema in 16 of the entire 288 patients treated with $\mathrm{I}^{131}$.

Five deaths occurred among the 288 patients within a period of days to several months following treatment-a remarkable record when one considers the severity of illness of some of the patients treated especially by Prinzmetal's and Haines' groups. Two of the five died of myo- 
cardial infarction, two of cerebral-vascular accidents and one of cardiac failure.

Apparently, severe progression of exophthalmos has not been a troublesome feature of radioiodine therapy. Soley, Miller, and Foreman (9) found a progression of $1.5 \mathrm{~mm}$. in 11 of 50 patients and an increase of 3 or more $\mathrm{mm}$. in four of the 50 while none showed a decrease of $1.5 \mathrm{~mm}$. or more. Thus $30 \%$ showed a significant increase in the prominence of their eyes. By way of comparison, 26\% of 75 hyperthyroid patients who received roentgenray therapy had progression of $1.5 \mathrm{~mm}$. or more and $6.6 \%$ showed a decrease of the same magnitude. Following subtotal thyroidectomy for Graves' disease, $40-50 \%$ of the patients had an increase in the prominence of their eyes of $1.5 \mathrm{~mm}$. or more.

Relapses after probably inadequate therapy have occurred in the experience of all investigators but true recurrences are rare, because the length of follow-up has not been of sufficient duration for recurrence to take place in well-treated patients.

\section{COMPARISON WITH OTHER METHODS OF TREATMENT}

Means (23) in 1946 appraised the modern methods of treating Graves' disease but did not have the advantage of recent published work with antithyroid drugs or radioactive iodine. $U p$ to the time of writing this paper, data still are not available to determine precisely the relative merits of (1) preparation of the patient with an antithyroid drug followed by subtotal thyroidectomy, (2) treatment with antithyroid drugs alone, (3) roentgen-ray treatment, and (4) treatment with radioiodine.

These various methods may be evaluated briefly as follows:

(1). In skilled hands with an efficient team, subtotal thyroidectomy in the well-prepared patient who has been on propyl thiouracil or one of the other thiouracil derivatives, carries a mortality of $0.5 \%$ or less and is accompanied by the hazards of parathyroid and recurrent laryngeal nerve injury in a small percentage of patients. In addition a varying number of patients will develop myxedema which can be treated readily with thyroid. The recurrence rate is under $5 \%$. Probably more patients can be treated successfully this way than by any single method.
(2). The commonly used thiouracils will in nearly all patients produce a satisfactory remission in Graves' disease. Thiouracil carries the same mortality hazard as subtotal thyroidectomy and in turn produces toxic effects in nearly $15 \%$ of patients, the most serious of which is agranulocytosis in approximately $2 \%$. Propyl thiouracil is much safer. However, after six to nine months of full remission, from perhaps $15 \%$ to over $50 \%$ of people will have a recurrence of hyperthyroidism when the drug is discontinued. The danger of neoplastic changes remains an unknown quantity. Advantages are the simplicity of therapy, the general satisfactory response of the patient and relatively low cost.

(3). Roentgen-ray therapy is not widely employed by thyroidologists, but has given good therapeutic responses in selected patients: those with moderate hyperthyroidism, with non-nodular goiters up to about 60 grams without complications such as coincident heart disease in which a rather slow return to normal might jeopardize the patient and with no history of sun-sensitivity or chronic laryngitis. The chief disadvantage is the comparatively long period required for complete remission. A great advantage is the absence of any mortality from the therapy itself.

(4). Radioiodine can be expected to produce satisfactory remissions in over $80 \%$ of patients and many of the other patients would (with less strict criteria than justifiably conservative observers have established) have had reasonably satisfactory end results. The only recorded deaths following $I^{131}$ were not related to the iodine therapy. No serious complications have been noted, but the possibility of late radiation change (tumors) has not been excluded. A disadvantage is the need for technical equipment and skilled personnel beyond that required for other methods of therapy.

Probably the most logical attitude for the therapist in Graves' disease is the recognition of at least four empirical but satisfactory types of treatment, any one of which or combinations of which should be selected for a given patient depending upon individual consideration of the patient and the special skills of the physician.

\section{SUMMARY}

An attempt has been made to present the total experience, to date, in the treatment of thyrotoxi- 
cosis with radioactive iodine. Although there are differences among various groups in the methods of treatment, the end results are quite similar and compare favorably with already accepted forms of therapy.

The use of radioactive materials in clinical medicine brings with it the necessity for specially trained personnel, and strict attention to the potential hazards of radiation both to patients and to physicians. In this, the relatively young era of isotope application, progress must be made slowly and carefully. It is not unlikely, however, that radioiodine therapy ultimately will come into more general use.

\section{BIBLIOGRAPHY}

1. Fermi, E., Radioactivity induced by neutron bombardment. Nature, 1934, 133, 757.

2. Hertz, S., Roberts, A., and Evans, R. D., Radioactive iodine as an indicator in the study of thyroid physiology. Proc. Soc. Exper. Biol. \& Med., 1938, 38, 510.

3. Hamilton, J. G., and Soley, M. H., Studies in iodine metabolism by the use of a new radioactive isotope of iodine. Am. J. Physiol., 1939, 127, 557.

4. Hertz, S., and Roberts, A., Application of radioactive iodine in therapy of Graves' disease. J. Clin. Invest., 1942, 21, 624.

5. Hamilton, J. G., and Lawrence, J. H., Recent clinical developments in the therapeutic application of radio-phosphorus and radio-iodine. J. Clin. Invest., 1942, 21, 624.

6. Chapman, E. M., and Evans, R. D., The treatment of hyperthyroidism with radioactive iodine. J. A. M. A., 1946, 131, 86.

7. Hertz, S., and Roberts, A., Radioactive iodine in the study of thyroid physiology. VII. The use of radioactive iodine therapy in hyperthyroidism. J. A. M. A., 1946, 131, 81.

8. Soley, M. H., and Miller, E. R., Treatment of Graves' disease with radioactive iodine. M. Clin. N. America, 1948, 32, 3.

9. Soley, M. H., Miller, E. R., and Foreman, N.,
Graves' disease: treatment with radioiodine $\left(I^{121}\right)$. J. Clin. Endocrinol., 1949, 9, 29.

10. Haines, S. F., Keating, F. R., Jr., Power, M. H., Williams, M. M. D., and Kelsey, M. P., The use of radioiodine in the treatment of exophthalmic goiter. J. Clin. Endocrinol., 1948, 8, 813.

11. Werner, S. C., Quimby, E. H., and Schmidt, C., The clinical use of radioactive iodine. Bull. New York Acad. Med., 1948, 24, 549.

12. Werner, S. C., Quimby, E. H., and Schmidt, C., Clinical experience in diagnosis and treatment of thyroid disorders with radioactive iodine (eightday half-life). Radiology, 1948, 51, 564.

13. Werner, S. C., Quimby, E. H., and Schmidt, C., Radioactive iodine $\mathrm{I}^{131}$ in the treatment of toxic goiter and as an indicator of thyroid function in man. Brookhaven Conf. Rep., BNL-C-5, July 1948, 69.

14. Prinzmetal, M., Agress, C. M., Bergman, H. C., and Simkin, B., The use of radioactive iodine in the treatment of Graves' disease. Unpublished paper.

15. Prinzmetal, M., Agress, C. M., Bergman, H. C., and Simkin, B., Problem cases of Graves' disease treated with radioactive iodine. Unpublished paper.

16. Crile, G., Jr., Practical Aspects of Thyroid Disease. W. B. Saunders Co., Philadelphia, 1949, 106-112.

17. Gorbman, A., Effects of radiotoxic dosages of $I^{\text {th }}$ upon thyroid and contiguous tissues of mice. Proc. Soc. Exper. Biol. \& Med., 1947, 66, 212.

18. Findlay, D., and LeBlond, C. P., Partial destruction of thyroid by large doses of radioiodine. Am. J. Roentgenol., 1948, 59, 387.

19. Marinelli, L. D., Dosage determinations with radioactive isotopes. Am. J. Roentgenol., 1942, 47, 210.

20. Quimby, E. H., Calculation of dosage in radioiodine therapy. Brookhaven Conf. Rep., BNL-C-5, July $1948,43$.

21. Marinelli, L. D., Quimby, E. H., and Hine, G. J., Dosage determinations with radioactive isotopes. Am. J. Roentgenol., 1948, 59, 260.

22. Chapman, E. M., Skanse, B. N., and Evans, R. D., Treatment of hyperthyroidism with radioactive iodine. Radiology, 1948, 51, 558.

23. Means, J. H., Evaluation of the several methods for treating Graves' disease available today, Ann. Int. Med., 1946, 25, 403. 